\title{
Superplastic Behaviour of an Extruded AZ91 Alloy
}

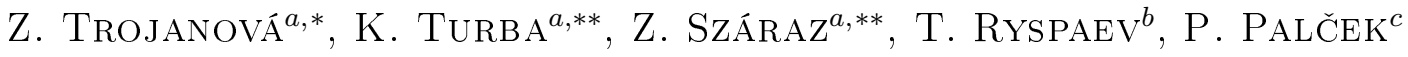 \\ And M. Chalupová ${ }^{c}$ \\ ${ }^{a}$ Department of Physics of Materials, Faculty of Mathematics and Physics, Charles University, Prague \\ Ke Karlovu 5, CZ-121 16 Praha 2, Czech Republic \\ ${ }^{b}$ Institute of Welding Engineering and Cutting Manufacturing Processes (ISAF), Clausthal University of Technology \\ Agricola Str. 2, D-38678 Clausthal-Zellerfeld, Germany \\ ${ }^{c}$ Department of Materials Engineering, Faculty of Mechanical Engineering, University of Žilina \\ Univerzitná 1, SK-010 26 Žilina, Slovak Republic
}

\begin{abstract}
Plastic deformation of extruded AZ91 magnesium alloy was investigated at various strain rates and in a temperature range of $360-420^{\circ} \mathrm{C}$. Samples exhibiting superplastic behaviour were prepared with different thermo-mechanical treatments. Microstructure of samples was observed by light and scanning electron microscopy. The strain rate sensitivity parameter $m$ has been estimated by the abrupt strain rate change method. Possible physical mechanisms of the superplastic flow are discussed.
\end{abstract}

PACS: $81.05 . \mathrm{Bx}, 62.20 . \mathrm{fq}$

\section{Introduction}

Magnesium alloys are promising materials for industrial applications because of their low density and high specific strength as well as good damping behaviour. Magnesium alloys are easy to recycle. It is expected that these materials become of special importance in many applications, especially in the transportation, electronic and aircraft industries. Engineering importance of magnesium alloys has risen recently. The strengthening of magnesium alloys is typically obtained by solubilisation and artificial ageing. As result of the industrial process, a polycrystalline material is obtained with a complex microstructure with precipitates inside grains, on the grain boundaries and dislocations. The commercial AZ91 alloy represents a frequently used magnesium casting alloy. AZ magnesium alloys based on this system ( $\mathrm{Mg}-\mathrm{Al}-$ $\mathrm{Zn}-\mathrm{Mn}$ ) have excellent castability. On the other hand, the ductility of these alloys at lower temperature is limited because of their hexagonal close packed structure (hcp) (common to most magnesium alloys). According to the von Mises criterion [1] the activity of five independent slip systems is required for plastic deformation

\footnotetext{
* corresponding author; e-mail: ztrojan@met.mff.cuni.cz
}

** Present address: Institute for Energy, Joint Research Centre, European Commission, P.O. Box 2, 1755ZG Petten, the Netherlands. of polycrystals. However, magnesium does not possess five independent crystallographically equivalent slip systems. The easy glide system is the basal slip system with $\langle a\rangle$ dislocations. These $\langle a\rangle$ dislocations may also glide in prismatic and first order pyramidal systems. All of the slip systems mentioned so far provides only a total of four independent slip systems [2]; none of them can produce strain parallel to the $c$ axis. This is possible only either in a second-order pyramidal slip system or by mechanical twinning [3]. The critical resolved shear stress (CRSS) in non-basal slip systems at lower temperatures is much higher in comparison with the CRSS for the basal slip. This is also the reason for the low ductility of hcp materials at low temperatures. The low ductility of magnesium alloys prevents their application; however, these limitations may be significantly reduced by finding the conditions for superplastic flow of $\mathrm{Mg}$ alloys. The key problem is to develop the fine-grained alloy with a low cost, low forming stress, low forming temperature and high forming rate.

In order to reduce grain size, several processes have been used: severe plastic deformation, powder metallurgy techniques, rapid solidification or hot rolling. An alternative route to prepare a superplastic alloy is thermo-mechanical treatment. Cast materials are heat-treated in two stages and processed by hot extrusion. The grain structure can be refined via recrystallisation in the alloy through ageing in combination with mechanical working during successive extrusion. The amount of knowledge regarding the characteristics and mechanisms of superplastic deformation in $\mathrm{Mg}$ alloys is lim- 
ited, which inhibits the proliferation of this forming process. The structural changes and deformation processes occurring during superplastic flow of the MA8 magnesium alloy $(\mathrm{Mg}-1.5 \mathrm{Mn}-0.3 \mathrm{Ce})$ were studied by Valiev and Kaibyshev [4, 5]. The superplasticity phenomenon has been observed in AZ31 (Mg-3Al-1Zn) [6-9], AZ61 [10], ZK60 [11], Mg-Li [12, 13], WE54 [14], QE22 [15], and EZ33 [16] alloys.

Although the superplastic behaviour of the AZ91 magnesium alloy has been reported by several authors [17-20], there is no satisfactory explanation of the physical processes occurring during the superplastic flow. The aim of this work is to contribute to this explanation investigating the influence of the thermo-mechanical treatment and deformation temperature on the strain rate sensitivity and superplastic behaviour of the AZ91 magnesium alloy.

\section{Experimental}

Commercial AZ91 (9Al-0.9Zn-0.4Mn-balance Mg, in wt\%) was used in this study. The as-received billets, produced from cast ingots, were heat-treated in two stages. The first step was a solution treatment at $415^{\circ} \mathrm{C}$ for $10 \mathrm{~h}$ followed by air quenching. Subsequently the billets were aged at temperatures of 200,300 and $380^{\circ} \mathrm{C}$ for $10 \mathrm{~h}$. Finally the billets were hot extruded at a temperature of $350^{\circ} \mathrm{C}$ to obtain rods.

Tensile specimens with a gauge length of $10 \mathrm{~mm}$ and a gauge diameter of $6 \mathrm{~mm}$ were machined with the tensile axis parallel to the extrusion direction. Abrupt strainrate jump tests in tension and tensile tests with a constant speed of crosshead displacement were carried out using an Instron 5582 universal testing machine. The deformation tests were carried out at 340,380 and $420^{\circ} \mathrm{C}$. The furnace temperature was controlled with an accuracy of $\pm 1{ }^{\circ} \mathrm{C}$. The microstructure of the extruded and deformed alloys was observed by light (LM) and scanning electron microscopy (SEM). The resulting materials after homogenization and precipitation ageing (at three temperatures: 200,300 and $380^{\circ} \mathrm{C}$ ) exhibited different grain sizes: $17 \mu \mathrm{m}$ (aged at $\left.200^{\circ} \mathrm{C}\right), 10.5 \mu \mathrm{m}\left(300^{\circ} \mathrm{C}\right)$ and $11 \mu \mathrm{m}\left(380^{\circ} \mathrm{C}\right)$.

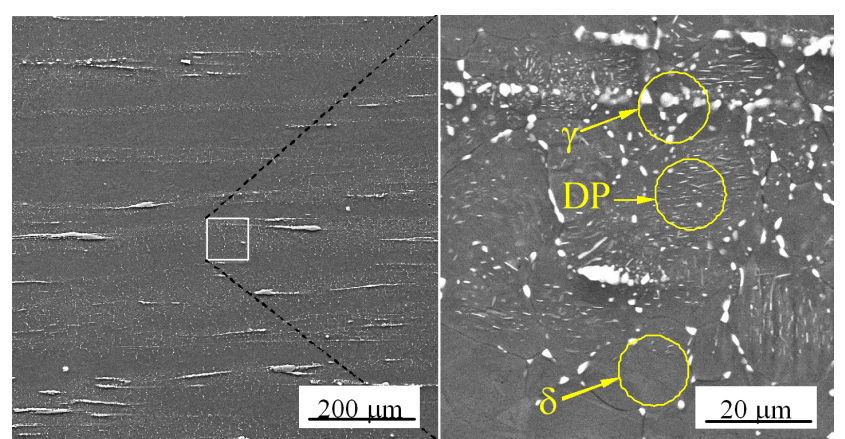

Fig. 1. Microstructure of AZ91 alloy after extrusion.
The microstructure of the material aged at $380^{\circ} \mathrm{C}$ is introduced in Fig. 1. The scanning electron micrograph was taken parallel to the extrusion direction. $\mathrm{Mg}_{17} \mathrm{Al}_{12}$ precipitates are visible in rows in the extrusion direction (left picture 1). Details of the microstructure are introduced in Fig. 1 (right): $\delta$-Mg grains (solid solution of $\mathrm{Al}$ in $\mathrm{Mg})$, primarily segregated $\gamma$-phase $\left(\mathrm{Mg}_{17} \mathrm{Al}_{12}\right)$ and discontinuous precipitates (DP). Microstructures of the materials aged at 200 and $300{ }^{\circ} \mathrm{C}$ were found to be very similar. The extruded samples exhibit a uniform grain structure; micrographs from sections parallel to the extrusion direction show the same grain size and grain shape. The grain refining depends on the temperature of the additional annealing in the second step.

\section{Results and discussion}

High values of the strain rate sensitivity of the flow stress $m$ represent one of the main features of superplastic deformation. The high values of $m$ as well as the elongation to failure $\varepsilon_{\mathrm{f}}$ are observed only in a certain region of the strain rates and temperatures. The strain rate sensitivity parameter $m$, defined as $m=\left(\frac{\mathrm{d} \ln \sigma}{\mathrm{d} \ln \dot{\varepsilon}}\right)_{T}$ was measured by the abrupt strain rate change test.

The values of the strain rate parameter $m$ estimated for various strain rates and temperatures for the material aged at $200^{\circ} \mathrm{C}$ are introduced in Fig. 2 .

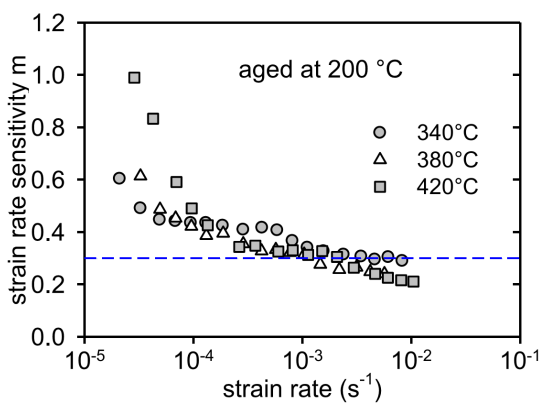

Fig. 2. Strain rate dependence of the strain rate sensitivity estimated at three temperatures for samples aged at $200{ }^{\circ} \mathrm{C}$.

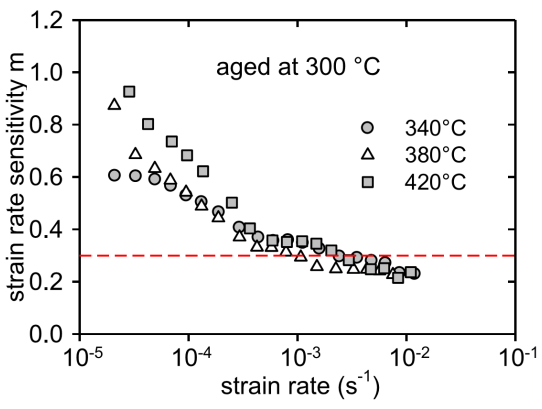

Fig. 3. As in Fig. 2, but at $300{ }^{\circ} \mathrm{C}$. 


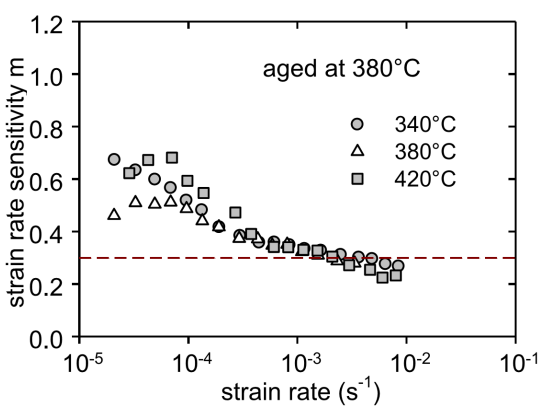

Fig. 4. As in Fig. 2, but at $380^{\circ} \mathrm{C}$.

Similar dependences estimated for materials aged at 300 and $380^{\circ} \mathrm{C}$ are shown in Figs. 3 and 4. A strong strain rate dependence of the $m$-parameter is obvious from Figs. 2-4. Usually, the $m$ value of 0.3 is considered as a limit of the superplastic behaviour i.e. superplastic deformation should be limited to strain rates between $3 \times 10^{-5}$ and $5 \times 10^{-3} \mathrm{~s}^{-1}$. Elongations to fracture obtained at various deformation temperatures for samples aged at three temperatures are introduced in Table. Let us note that values estimated at $420^{\circ} \mathrm{C}$ were obtained in experiments with a constant strain rate [21].

TABLE

Elongation to fracture estimated for various ageing and straining temperatures.

\begin{tabular}{c|c|c|c}
\hline \hline $\begin{array}{c}\text { Ageing } \\
\text { temperature } \\
{\left[{ }^{\circ} \mathrm{C}\right]}\end{array}$ & $\begin{array}{c}\text { Straining } \\
\text { temperature } \\
{\left[{ }^{\circ} \mathrm{C}\right]}\end{array}$ & $\begin{array}{c}\text { Elongation } \\
\text { to fracture } \\
{[\%]}\end{array}$ & $\begin{array}{c}\text { Strain rate } \\
{\left[\mathrm{s}^{-1}\right]}\end{array}$ \\
\hline 200 & 340 & 201 & $3 \times 10^{-4}$ \\
200 & 380 & 285 & $3 \times 10^{-4}$ \\
200 & 420 & 413 & $1 \times 10^{-4}$ \\
300 & 340 & 291 & $3 \times 10^{-4}$ \\
300 & 380 & 280 & $3 \times 10^{-4}$ \\
300 & 420 & 484 & $1 \times 10^{-4}$ \\
380 & 340 & 260 & $3 \times 10^{-4}$ \\
380 & 380 & 251 & $3 \times 10^{-4}$ \\
380 & 420 & 584 & $1 \times 10^{-4}$
\end{tabular}

The maximum elongation of $584 \%$ was obtained at $420^{\circ} \mathrm{C}$ and $1 \times 10^{-4} \mathrm{~s}^{-1}$ for the sample aged at $380^{\circ} \mathrm{C}$ with a corresponding value of the strain rate sensitivity $m=0.68$. The tensile elongations of all samples exceeded $200 \%$, which represents a substantial improvement over the poor room-temperature ductility, typical for magnesium alloys.

The microstructure of the sample deformed at $340^{\circ} \mathrm{C}$ and aged at $380^{\circ} \mathrm{C}$ is introduced in Fig. 5. Many cavities are visible in the bottom and upper part of the picture. Grains in the vicinity of cavities slightly grew while grains in the middle part remained unchanged. Twins are present practically in all grains after deformation. It indicates that no recrystallisation occurred during the high

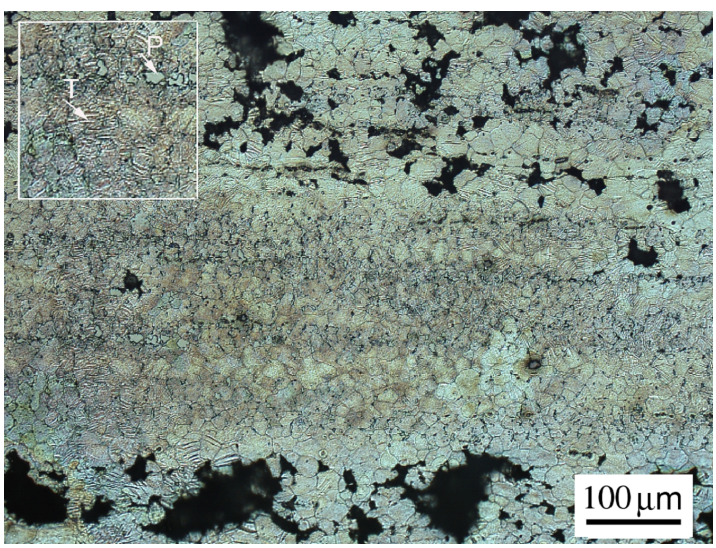

Fig. 5. Microstructure of sample aged at $380^{\circ} \mathrm{C}$ and strained at $340{ }^{\circ} \mathrm{C}$. In the inset $\mathrm{P}$ indicates precipitated particle and $\mathrm{T}$ - deformation twins.

temperature deformation. This result is different from our previous observation where no twins were estimated in the samples deformed at $420^{\circ} \mathrm{C}$ [21]. Bands of cavities oriented in the extrusion direction are visible in Fig. 6. They are distributed along grain boundaries or around interfaces between the magnesium matrix and the fine particles of the $\gamma$-phase. An oriented microstructure of the $\gamma$-phase was created after hot extrusion, particles of the second phase were broken into finer particles and arranged into bands. The formation and growth of cavities relaxes the stress concentration in triple junctions caused by grain boundary sliding (GBS).

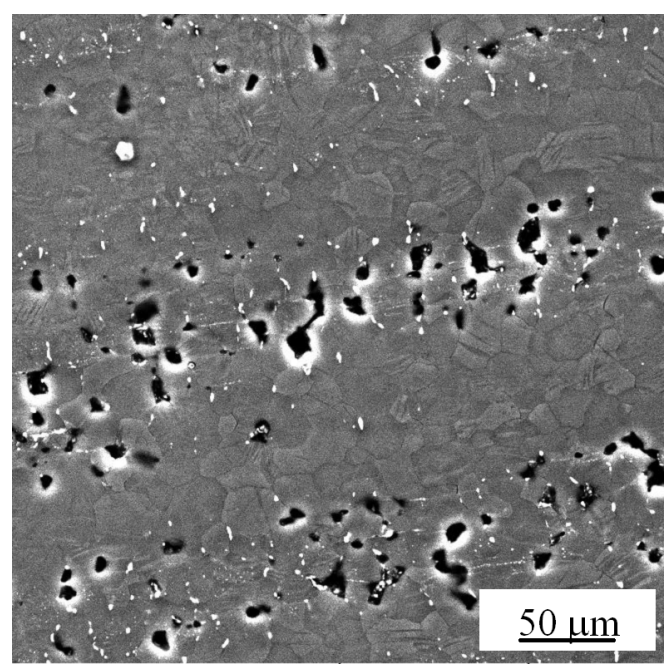

Fig. 6. Cavities in the sample deformed at $340{ }^{\circ} \mathrm{C}$.

Stress concentrations are likely to develop at sites which impede grain boundary sliding such as grain boundary particles, ledges and triple points. Cavities, created by vacancy clustering, may nucleate if the stress concentration is not relieved sufficiently rapidly. The AZ91 alloy with the intermetallic inclusions can be con- 
sidered as a natural composite. The stress concentrations are caused at the particles on sliding grain boundaries. Local tensile stress caused by sliding at interfaces may be written in the form [22]

$$
\sigma_{\text {slid }}=\frac{0.92 k T d_{\mathrm{p}} \dot{\varepsilon} \mathrm{d} V_{\mathrm{f}}}{\Omega D_{\mathrm{L}}\left(1+5 \frac{\delta D_{\mathrm{GB}}}{d_{\mathrm{p}} D_{\mathrm{L}}}\right)},
$$

where $d_{\mathrm{p}}$ is the particle diameter, $\dot{\varepsilon}$ - the strain rate, $d$ - the grain size, $D_{\mathrm{L}}$ - lattice diffusion and $D_{\mathrm{GB}}$ - the grain boundary diffusion coefficient, $\delta$ - grain boundary width, $\Omega$ - atomic volume. $V_{\mathrm{f}}$ is the volume fraction of particles and $k T$ has its usual meaning. The twins observed after deformation at $340^{\circ} \mathrm{C}$ provide evidence that in $\mathrm{Mg}$ alloys, twinning may serve as an additional accommodation mechanism for GBS at straining temperatures which do not allow for sufficiently fast diffusion-related accommodation.

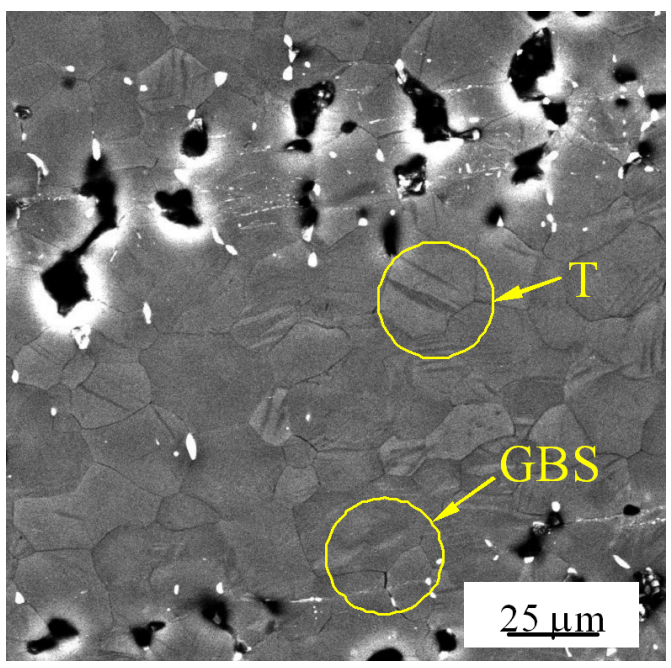

Fig. 7. Grain boundary sliding and twins in the sample deformed at $340^{\circ} \mathrm{C}$.

The insufficiently accommodated GBS process is documented in Fig. 7, where a small crack was created as a result of the GBS. The presented results allow us to conclude that GBS is the main deformation mechanism during the superplastic deformation of the studied alloy at 340 and $380^{\circ} \mathrm{C}$ and at the strain rate of $3 \times 10^{-4} \mathrm{~s}^{-1}$. The different thermo-mechanical treatment influenced the samples microstructure and also different contributions to the superplastic flow: GBS, lattice (grain boundary) diffusion, and dislocation deformation (creep and climb of dislocations). In addition to the known mechanisms of superplastic deformation, mechanical twinning was observed.

\section{Conclusions}

Superplastic deformation of an extruded AZ91 magnesium alloy was observed at 340,380 and $420^{\circ} \mathrm{C}$ and at strain rates of $13 \times 10^{-4} \mathrm{~s}^{-1}$ and $3 \times 10^{-4} \mathrm{~s}^{-1}$. Grain boundary sliding is very probably the main mechanism responsible for the superplastic flow. Mechanical twinning was found as a new accommodating mechanism.
The prior thermo-mechanical treatment has a significant influence on the resulting superplastic behaviour.

\section{Acknowledgments}

This work is a part of the research project MSM 0021620834 that is financed by the Ministry of Education, Youth and Sports of the Czech Republic. The support of the Grant Agency of the Academy of Sciences of the Czech Republic by the grant No. IAA201120902 is also greatly acknowledged.

\section{References}

[1] R. von Mises, Z. Angew. Math. Mech. 8, 161 (1928).

[2] M. Knezevic, A. Levinson, R. Harris, R.K. Mishra, R.D. Doherty, S.R. Kalidindi, Acta Mater. 58, 6230 (2010).

[3] K. Máthis, J. Čapek, Z. Zdražilová, Z. Trojanová, Mater. Sci. Eng. A 528, 5904 (2011).

[4] R.Z. Valiev, O.A. Kaibyshev, Phys. Status Solidi A 44, 477 (1977).

[5] R.Z. Valiev, O.A. Kaibyshev, Phys. Status Solidi A 45, 77 (1978).

[6] A. Bussiba, A. Ben Artzy, A. Shtechman, S. Ifergan, M. Kupiec, Mater. Sci. Eng. A 302, 56 (2001).

[7] D.L. Yin, K.F. Zhang, G.F. Wang, W.B. Han, Mater. Lett. 59, 1714 (2005).

[8] J.C. Tan, M.J. Tan, Mater. Sci. Eng. A 339, 81 (2003).

[9] J.C. Tan, M.J. Tan, Scr. Mater. 47, 101 (2002).

[10] M. Mabuchi, K. Ameyama, H. Iwasaki, K. Higashi, Acta Mater. 47, 2047 (1999).

[11] D.L. Yin, K.F. Zhang, G.F. Wang, W.B. Han, Mater. Lett. 59, 1714 (2005).

[12] M. Furui, C. Xu, T. Aida, M. Inoue, H. Anada, T.G. Langdon, Mater. Sci. Eng. A 410-411, 439 (2005).

[13] O. Sivakesavam, Y.V.R.K. Prasad, Mater. Sci. Eng. A 323, 270 (2002).

[14] K. Nakashima, H. Iwasaki, T. Mori, M. Mabuchi, M. Nakamura, T. Asahina, Mater. Sci. Eng. A 293, $15(2000)$.

[15] V. Wesling, T. Ryspaev, A. Schram, Mater. Sci. Eng. A 462, 144 (2007).

[16] T. Ryspaev, Z. Trojanová, O. Padalka, V. Wesling, Mater. Lett. 62, 4041 (2008).

[17] M. Mabuchi, H. Iwasaki, K. Yanase, K. Higashi, Scr. Mater. 36, 681 (1997).

[18] V.N. Chuvil'deev, T.G. Nieh, M.Yu. Gryaznov, V.I. Kopylov, A.N. Sysoev, J. Alloys Comp. 378, 253 (2004).

[19] Y.H. Wei, Q.D. Wang, Y.P. Zhu, H.T. Zhou, W.J. Ding, Y. Chino, M. Mabuchi, Mater. Sci. Eng. A 360, 107 (2003).

[20] Z. Száraz, Z. Trojanová, T. Ryspaev, V. Wesling, Mater. Sci. Forum 567-568, 365 (2008).

[21] Z. Trojanová, Z. Száraz, T. Ryspaev, V. Wesling, Kovove Mater. 46, 285 (2008).

[22] M. Mabuchi, K. Higashi, Acta Mater. 47, 1915 (1999). 